\title{
WITTGENSTEIN E O ARGUMENTO DA LINGUAGEM PRIVADA
}

\author{
Luziano Pereira Mendes de Lima (UNICAMP) ${ }^{1}$
}

\section{O Tractatus e as Investigações}

O pensamento de Wittgenstein em sua "última" fase ${ }^{2}$ desenvolve-se como uma "crítica radical à tradição filosófica ocidental da linguagem, cuja expressão última havia sido o Tractatus" (Oliveira, 1996:117). Sua obra Investigações Filosóficas ${ }^{3}$ coloca-se em oposição fundamental a sua primeira, embora mantendo o mesmo problema central ${ }^{+}$: a pergunta pelo significado das expressões lingüísticas.

Conforme Oliveira (1996:119-120):

... a linguagem sempre foi vista pela tradição como uma mediação necessária. Nesse sentido, poder-se-ia falar que a linguagem é condição de possibilidade da comunicação do resultado do conhecimento humano, porém nunca, também não no Tractatus, é condição de possibilidade do próprio conhecimento humano, pois, pelo menos implicitamente,

O presente trabalho é fruto dos estudos realizados na disciplina de Filosofia da Linguagem, ministrado pelo professor Arley Moreno. Agradeço ao professor Arley pelos encontros com Wittgenstein. Agradeço à professora Mônica Graciela Zoppi-Fontana pela leitura e observações críticas sobre o texto.

2 J. Hintikka e M. Hintikka (1994:185-186) assumem a posição - que pretende encerrar o debate proposto por G. H. von Wright sobre a continuidade ou não entre o Wittgenstein do Tractatus e o das Investigações - que defende a existência de dois Wittgenstein, ao mesmo tempo que sustentam haver uma continuidade entre o Wittgenstein do Tractatus e o das Investigações Filosóficas. Tal posição, segundo eles, contrapõe-se à de Anthony Kenny, que afirmava poder "haver apenas um. ou talvez très, mas certamente não exatamente dois, como julga a opinião comum".

3 Doravante IF.

4 (IF - Prefácio; Oliveira, 1996:117; Moreno, 2000:54; J. Hintikka e M. Hintikka, 1994:190) 
contrariando talvez alguma afirmação explicita, Wittgenstein aceita no Tractatus a tese tradicional do caráter secundário, designativo da linguagem humana. Wittgenstein não vai negar 0 caráter designativo da linguagem, mas vai rebelar-se, fortemente, contra o exagero da tradição - posiçäo assumida tambèm no Tractatus - de ver na designação a principal e até mesmo a única função da linguagem. Precisamente nisso vai consistir para ele a limitação da filosofia ocidental da linguagem. Essa teoria designativa da linguagem assumiu duas formas: hà os que afirmam que as palavras designam pura e simplesmente as coisas singulares, pois, além de coisas singulares e palavras, nada existe. Ou, então, numa outra linha muito mais forte na tradição ocidental, diz-se que com uma palavra se podem designar muitas coisas, porque as palavras designam não coisas singulares, mas a essência comum a muitas coisas. 0 comum a todas elas é a essência... seu "conceito".

Para o Wittgenstein do Tractatus (1995), "A imagem é um modelo da realidade" (T. $\$$ 2.12). "A proposição é um modelo da realidade tal como nós a pensamos" $(\$ 4.01)$ e a linguagem corrente é imprecisa, complicada e, por isso, freqüentemente suscetivel a erros $(\$ 3.323,3.324$ e 4.002$)$. Para evitar tais erros e confusóes, propunha que utilizássemos uma linguagem simbólica, ideal (\$ 3.325). Tais atirmações, de certo modo, apontam para a busca de precisão da linguagem através do "modelo de um cálculo lógico" e do "caráter designativo das palavras" ". Wittgenstein começa as Imestigaçoóes Filosóficas (1995) exatamente pela exposição e pela crítica do caráter designativo das palavras, isto é, pela exposição e pela crítica da concepção agostiniana da linguagem, pela crítica da posição essencialista e metafísica da linguagem. No entanto, é necessário notar que o processo de mudança ocorrido no pensamento de Wittgenstein não significa o abandono de todo seu pensamento anterior, mas un aprofundamento, um alargamento. Conforme Oliveira (1996:132):

Nāo è que uma linguagem exata, construida artificialmente, tenha perdido todo o sentido para o Wittgenstein da segunda fase. Ela continua um instrumento de grande importância na ciência natural. Contudo, não pode ser considerada o paradigma lingüistico enquanto tal, como foi o caso no Tractatus. Depois, uma vez tendo sido relativizada a função

Oliveira, 1996:121-122. Frege (1892) sustenta, também, a visão negativa sobre a possibilidade de produzir conhecimento verdadeiro a partir das linguas naturais, quando defende a construção de uma ideografia, linguagem simbólica perfeita. 
designativa da linguagem, ela aparece agora apenas como uma entre muitas funções possiveis da linguagem. $O$ importante agora è ver nossa linguagem, para ai descobrir como ela, de fato, è usada, e não especular a priori. O ponto de partida, o ponto de referência, o cerne da reflexão de Wittgenstein deixa de ser a linguagem ideal para se tornar a situação na qual o homem usa sua linguagem; então, o único meio de saber o que é a linguagem é observar seus diferentes usos.

Esta última posição de Wittgenstein contrapõe-se por um lado a una teoria metafísica da linguagem, atacando diretamente as posições idealistas e, por outro lado, introduz uma posição pragmática no tocante à linguagem. Exemplo da posição à qual Wittgenstein se contrapõe se encontra na obra de René Descartes. Sabemos que, tradicionalmente, a linguagem é um dos elementos fundamentais que distingue o homem dos demais seres vivos. Descartes (1996:112), por exemplo, na quinta parte de seu Discurso do Método, afirmava:

...pode-se também conhecer a diferença existente entre os homens e os animais. Pois é uma coisa bem notável que não haja homens tão embrutecidos e tão estúpidos. sem excetuar mesmos os insanos, que não sejam capazes de arranjar em conjunto diversas palavras, e de compô-las num discurso pelo qual façam entender seus pensamentos; e que ao contrário, não exista outro animal, por mais perfeito e felizmente engendrado, que possa fazer o mesmo.

Conforme sabemos, a incapacidade dos animais para construção de uma linguagem articulada, segundo Descartes, não ocorre devido à falta de órgãos, visto que as pegas e os papagaios produzem sons, emitem "palavras", mas não podem falar como nós. No entanto. "... os homens que, tendo nascido surdos e mudos. desprovidos dos órgãos que servem aos outros para falar, tanto ou mais que os animais, costumam inventar eles próprios alguns sinais, pelos quais se fazem entender por quem, estando comumente com eles, disponha de lazer para aprender a sua lingua" (Descartes. 1996:112) [Grifos meus]. Estas últimas frases podem levar o leitor a concluir pela possibilidade de uma linguagem privada, que o homem, isoladamente, criaria como uma linguagem própria. Posição que se sustentaria num fundamento metafísico e idealista, tendo em vista que, para Descartes, a diferença entre o homem e as demais espécies animais está em que o homem tem uma alma racional alojada no corpo. O pensamento e a linguagem, esta última enquanto expressão daquele, seriam, assim, atos da alma, atos do espírito. O pronunciar 
palavras é uma atividade física (tal como fazem pegas e papagaios), mas o pensar, o articular uma linguagem é uma atividade espiritual, uma atividade da razão.

A posição dualista de Descartes é marcante no que se refere à linguagem. Conforme Oliveira (1996:133):

O dualismo caracterizou-se na concepção da linguagem como fenômeno complexo de dupla dimensão: a realidade fisica produzida por atos corpóreos deve ser, para se tornar linguagem humana, acompanhada por certos atos espirituais, processos internos (manifestações lingüisticas do dualismo corpo-espirito). Somente por meio da transformação efetuada por esses atos espirituais as palavras têm, propriamente, significação. Isso é, portanto, o dualismo entre sentido e produção dos sons. A toda expressão acústica pertence um mecanismo interior, espiritual.

Contrapondo-se a essa posição, a posição tradicional, Wittgenstein colocara em discussão a questão da possibilidade da linguagem privada. Pois, conforme a tradição, os "atos espirituais são estritamente privados, uma vez que, diretamente, só seu produtor tem acesso a eles". Embora se conceba que a "coincidência na identidade da significação das palavras é fruto da convenção, já que, em princípio, cada um poderia ter sua própria linguagem. Em todo caso, fundamental na teoria tradicional da linguagem é que a significação das palavras provém do ato subjetivo e interior ao espírito" (Oliveira, 1996:122-123).

\section{O Argumento da Linguagem privada}

O famigerado argumento sobre a possibilidade da linguagem privada, ao qual Wittgenstein vai se opor, aparece formulado nas Investigações Filosóficas $(\S 243)$ da seguinte maneira: “(...) As palavras desta linguagem devem relacionar-se com o que só quem fala pode saber; isto é, com suas sensações imediatas e privadas. Portanto, outra pessoa não pode entender esta linguagem".

Tradicionalmente, considera-se que a principal contestação da posição acima descrita será realizada entre as seções 244 e 271 das Investigações Filosóficas. Essas seções, em especial a § 256, ficariam conhecidas como o argumento da linguagem privada. Muito embora alguns autores, por exemplo, Saul Kripke, que parece ter sido o primeiro, contestam o início do argumento contra a linguagem privada 
a partir da \$243. Em seu livro Règles et Langage Privé: introduction au paradoxe de Wittgenstein (edição francesa de 1996), publicado originalmente em inglês no ano de 1982, afirma:

On considère d'ordinaire que $\mathrm{l}$ '<<argument du langage privé>> commence au $\S 243$ des Investigations philosophiques, et se poursuit dans le sections suivantes. Dans cette perspective, l'argumentation apparaît comme essentiellement lièe à un problème posé par le <<langage des sensations >>.(...) Certains passages cruciaux dans les développements que suivent le $\S$ 243 - par exemple les célèbres sections 258 et 265 - sont restés notoirement obscurs pour les commentateurs, et il est généralement admis qu'interprétés correctement ils nous fourniraient la clé de l'<<argument du langage privé>>.

Quant à moi, je soutiens que le véritable $<<a r g u m e n t ~ d u$ langage privè > se trouve dans les sections qui précèdent le $\S$ 243. De fait, au $\S 202$, sa conclusion est déjà énoncée explicitement: $<<\|$ n'est donc pas possible d'obéir à une règle "en son for intérieur: sinon penser qu'on obéit à une règle serait la même chose que lui obéir. (Kripke, 1996:12-13).

No entanto, apesar das afirmações de Kripke e contra elas, Hans-Johann Glock (1998:230), em seu Dicionário Wittgenstein (1998), argumenta que:

A noção de uma linguagem privada surge primeiramente nas preleções de 1935-6 (LPE ${ }^{6}$; LSD $\left.{ }^{7}\right)$; o argumento contra essa noção é desenvolvido em manuscritos de 1937 e completado em 1944-5.

A versão final, aprimorada porém condensada, encontra-se nos parágrafos 243 a 315 das Investigações. Essa localização foi negada por alguns adeptos de uma visão comunitarista da atividade de seguir REGRAS, que alegavam que o "verdadeiro»" argumento da linguagem privada já se encontra completo por ocasião do $\S 202$, quando se afirma que «não podemos seguir uma regra "privadamente": do contrário, pensar que se está obedecendo a uma regra equivaleria a obedecê-la». Nessa ótica, os §§ 243-315 apenas defendem a idéia de que o discurso dotado de significado supōe uma comunidade real de falantes, contra o possivel contra-exemplo dos termos

O autor refere-se ao texto "Wittgenstein's Notes for Lectures on Private Experience and Sense Data" [1936], org. R. Rhees, Philosophical Review, 77 (1968), 275-320.

Trata-se do texto "The Language of Sense Data and Private Experience -Notes taken by R. Rhees of Wittgenstein's Lectures, 1936", Philosophical Investigations, 7 (1984), 1-45, 101-140. 
designadores de sensaçōes. Entretanto, nos rascunhos originais (MS 180 a 68-72; MS129 116-17), o §202 acompanha e pressupōe os $\S \S 243-315$. Além disso, a discussão sobre a linguagem privada encontrada nos §§ 243-315 não diz respeito a produtores de monólogos, que não comunicam suas sensaçōes. Finalmente, essa discussão não se limita a aplicar às sensações uma lição sobre a atividade de seguir uma regra; tenta antes desfazer equivocos gerais acerca da mente (estados e processos mentais) e de sua relação com o comportamento. Embora seu foco principal recaia sobre as sensações (Empfindungen), e em particular sobre a dor, ocupase igualmente da experiência, em especial, das experiências visuais $\left(\mathrm{PI}^{9} \S \S 273-80,290,305-6,312\right)$.

Por outro lado, o argumento da linguagem privada realmente pressupõe a discussão anterior sobre o que é seguir uma regra. Uma discussão sobre a coerência da noção de linguagem privada pressupõe uma concepção de linguagem, e Wittgenstein considera a linguagem como uma atividade guiada por regras GRAMATICAIS.

Pelo acima exposto, sem a pretensão de encerrar o debate em torno dessa questão, observamos que, no tocante ao argumento da linguagem privada, o percurso de Wittgenstein a partir da seção 243 das Investigaçóes Filosóficas parece-nos ser o mais plausivel.

O argumento desenvolvido por Wittgenstein na $\$ 243$ não se refere a uma linguagem enquanto código pessoal, falado por uma só pessoa, muto menos de una linguagem utilizada somente em monólogos, mas sim. de uma linguagem que por principio não pode ser compartilhada ou ensinada, visto que a «referência das palavras daquela linguagem deve ser considerada ser aquilo de que só a pessoa que fala pode saber; as suas sensações imediatas privadas». Esta afirmação de Wittgenstein pode ser considerada sob dois aspectos para os quais Smith (1995:340) nos chama a atenção. Diz ele:

(...) Por um lado, a linguagem privada tem um sentido epistemológico, pois suas palavras se referem àquilo que apenas o falante pode conhecer, e uma outra pessoa poderia, no máximo, supor o que eu tenho; e, por outro, tem um sentido ontológico, uma vez que ela se refere a sensações que pertencem ao falante e não podem ser possuidas por ninguém:

Refere-se a escritos não publicados, manuscritos.

Refere-se a Philosophical Investigations [edição bilingüe alemào-inglês], org. G. E. M. Anscombe e R. Rhees, trad. G. E. M. Anscombe (Oxford: Blackwell, 1958, primeira edição em 1953). 
ao contrário de um carro... a posse das sensações é intransferivel e pessoal.

Wittgenstein atacou essa idéia de uma linguagem privada principalmente nas seções 244-271 das Investigações Filosóficas. Estas passagens, em especial a $\$ 256$ e seguintes, são conhecidas como «o argumento da linguagem privada».

É importante notar que Wittgenstein, no percurso que tem início na seção 244, faz implicitamente menção a um critério público particular no qual podemos nos apoiar para falar acerca de nossas vivências privadas. $\mathrm{Na} \$ 244 \mathrm{diz}$ Wittgenstein:

Como é que as palavras referem sensações? Ai não parece haver qualquer problema; não falamos todos os dias de sensações, não thes damos nomes? Mas como é que a conexão entre o nome e a sensação é estabelecida? Essa pergunta è igual a esta: como é que uma pessoa aprende a denotação dos nomes das sensações? Por exemplo: da palavra $<<$ dor $>>$. Eis uma possibilidade: estabelecer uma conexão entre a palavra e a expressão primitiva, natural, da sensação, e substituir a expressão natural pela palavra. Uma criança fere-se e grita; os adultos falam com ela, ensinam-lhe a fazer exclamação e, mais tarde, a dizer frases. Ensinam à criança um novo comportamento de dor.

... a expressão verbal da dor substitui o grito, não o descreve.

A afirmação: "Eis uma possibilidade..." aponta na direção de que há aqui várias possibilidades distintas para a 'existência de diversos jogos de linguagem possiveis.

Wittgenstein se questiona: "Como é que as palavras referem sensações?... como é que a conexão entre o nome e a sensação é estabelecida?» (\$ 244). E mais adiante: «Até que ponto as minhas sensações são privadas?» (\$ 246). Para responder a tais questões, Wittgenstein vai lançar mão dos jogos de linguagem (pelo seu caráter público), que possibilitam a representação dos estados mentais. A possibilidade de uma linguagem privada se sustentaria, conforme o exemplo da dor, tomando por base a idéia de que só aquele que sente a dor pode ter certeza de que a sente, enquanto os outros podem apenas conjecturar. O conhecimento que os outros podem ter da dor dele jamais seria do mesmo nível do que temos do mundo físico exterior. Uma das diferenças entre a linguagem privada e a linguagem cotidiana 
é o fato de ela não dispor do comportamento natural dos homens para explicar o significado das palavras. Segundo Smith (1995:341):

(...) $\mathrm{Na}$ linguagem privada, naturalmente não dispomos do comportamento ou da expressão natural dor para explicar o significado da palavra "dor», pois nesse caso ela não seria privada no sentido exigido, uma vez que o comportamento é público e acessivel a outros homens. O modelo da linguagem privada me permite dispor de somente dois elementos: a sensação e o nome para a sensação. Isso implicará, pelo menos, duas diferenças entre a linguagem privada e a linguagem comum.

$\mathrm{Na}$ seção 256 das Investigações Filosóficas. Wittgenstein sugere que a relação de um nome com uma sensação é privada apenas quando essa relação se baseia no modelo designativo, isto é, de forma que não se ligue às minhas exteriorizações naturais das sensações.

$\mathrm{Na}$ seção 257, Wittgenstein vai além das questões de comunicabilidade interpessoal dos nomes das sensações, chegando à concepção de uma "gramática» em geral, isto é, chamando a atenção para o fato de que falar uma língua é, entre outras coisas, participar de uma atividade guiada por regras. Neste sentido, diz Wittgenstein:

"Como seria se as pessoas não exteriorizassem (não gemessem, não contraissem o rosto) as suas dores? Então, não seria possivel ensinar a uma criança o uso da expressão dor-de-dentes». - Bem, suponhamos que a criança é um génio e inventa ela própria um nome para a sensação! - Mas então com esta palavra ela não poderia fazer-se compreender. Então a criança compreende o nome, mas não é capaz de explicar qual é sua denotação? - Mas o que é então o que ela faz ao "dar um nome à dor»? Como é que ela fez isso? Dar um nome à dor?! E seja o que for que ela fez, que finalidade tem? Quando se diz "Ela deu nome à sensação» esquece-se que, na linguagem, já tem que haver muito trabalho preparatório para que o simples «dar nome» tenha sentido. E quando dizemos que uma pessoa dá nome a uma dor, então o trabalho preparatório é a gramática da palavra «dor»; mostra o posto em que a nova palavra será colocada.

Em seguida, Wittgenstein nos convida a imaginar que alguém decida escrever o símbolo ' $\mathrm{S}$ ' no calendário dele sempre que the ocorre uma certa sensação. Esta sensação não tem nenhuma expressão, e 'S' não pode ser definido em palavras. A única pessoa que pode julgar se 'S'é usado de forma correta é aquela que inventou o símbolo 
· S': não há um critério externo que o justifique. «Bem, eu creio que esta é de novo a sensação S». - Sim, tu crês que crês!” (I. F. - \$ 260). l: pode fazer ' $S$ ' significar tudo o que ele quiser. Assim sendo, não há nenhum certo ou errado ao uso dele. Ele poderia muito bem ao escrever ' $S$ ' estar rabiscando. Dizer por exemplo (I. F. - \$258):

«Gravo-a em mim próprio»(a sensação) só pode de facto significar o seguinte: o processo de gravar faz com que eu no futuro me lembre correctamente da conexão. Mas no nosso caso não tenho critério para determinar a correcção. Aqui apetecia dizer: correcto é tudo o que me pareça correcto. $E$ isto significa apenas que não se pode falar aqui de «correcto».

Essa observação, lembra Glock (1998:232), já foi interpretada como calcada numa atitude cética com relação à memória. Ao que, segundo ele, os wittgensteinianos teriam retorquido que tal falibilidade ć inofensiva se os erros puderem ser corrigidos, o que não é possivel no caso privado. Ainda segundo Glock, o erro, tanto daqueles que atacam como dos que defendem Wittgenstein, estaria no fato de associarem a passagem acima citada ao ceticismo e à memória. "O que está em questão não é a verdade que há em proferir a sentença "Eis ai ' $\mathrm{S}$ ' novamente», mas sim seu sentido". Mais adiante, enfatiza ele:

Wittgenstein não argumenta, entretanto, que nos seja impossivel saber se o lingüista privado está ou não aplicando a regra corretamente; o que afirma è que, nem mesmo para ele, foi estabelecida uma regra de uso para "S».

Na seção 265 das Investigações Filosóficas, Wittgenstein critica a idéia de que a correção da imagem mental poderia ser testada tomando por base «uma tabela. um pouco como um dicionário, mas que apenas existia na nossa mente». Pois a tentativa de justificar uma memória bascada em outra não consegue com isso ultrapassar a pura subjetividade. nào podendo assim distinguir objetivamente o uso correto do incorreto de uma palavra. Afirmação semelhante aparece também na objeção à linguagem privada feita na seção 268 , mostrando que a "mão direita não pode dar dinheiro à mão esquerda". E mesmo que fosse possível, não teria isto os resultados práticos de uma doação, por exemplo. O que é alirmado aqui não é a falibilidade de se olhar para uma tabela imaginária, ou que esta seja mais falivel que uma tabela materializada. Novamente acpui, poderíamos dizer com Glock que a referência quanto a uma atitude cílica com relação à memória ou a identificação mental, não teria sentido. 
Conforme nos mostra Smith (1995:362), na linguagem dá-se exatamente o contrário:

$\mathrm{Na}$ linguagem comum... dispomos de critérios do comportamento para saber se uma pessoa entendeu uma palavra, se apenas parece ter entendido uma palavra, mas não a entendeu realmente e se ela não entendeu nada (PhU § 269).

O percurso traçado por Wittgenstein, em especial nas seções (258, 264-5, 293), mostra, de diversas maneiras, através de diversos exemplos, que o modelo designativo não pode dar conta da linguagem que usamos em nossas vivências privadas, ou, por outro lado, que precisamos de um critério público para falar sobre elas, de modo que, independente desses critérios nossas denominações das sensações não teriam função (conforme seções 253-254, 270-271, 281, 283). É importante notar que neste percurso realizado por Wittgenstein nas Investigações Filosóficas - I, seções 243-315, a novidade não se encontra nas críticas por ele desenvolvidas, mas na afirmação implícita de que são os jogos de linguagem que conferem significados às nossas falas sobre as diversas sensações ${ }^{10}$.

Embora seja considerado tradicionalmente pela maioria dos intérpretes que o argumento sobre a linguagem privada se encontra entre as seções 243-315, pode-se observar que ele reaparece reformulado no sentido de aprofundamento em diversas outras seções posteriores. Não pretendo seguir aqui todos os passos de Wittgenstein, mas alguns poucos exemplos podem demonstrar a persistência e tratamento terapêutico aplicado ao argumento sobre outras formas.

Na seção 344, por exemplo, Wittgenstein coloca novamente em debate a típica questão defendida pelas posições idealistas, qual seja: da independência do pensamento em relação à linguagem. Wittgenstein explicita ai, sob uma nova forma, o argumento idealista da linguagem privada, ou seja, que só o individuo que utiliza essa linguagem compreende suas significações. Opondo-se a essa idéia, Wittgenstein sustentará que o pensamento é uma linguagem pública, só que não articulada oralmente. Mas qual é o critério que poderia determinar se uma pessoa está a falar para si própria, interiormente ou não? Wittgenstein diz:

III J. Hintikka e M. Hintikka, 1994:335. 
O nosso critério para determinar se uma pessoa fala para si própria é o que ela nos diz e o seu comportamento; e só dizemos de uma pessoa que ela fala para si própria se ela, no sentido usual, è capaz de falar. Também não o dizemos de um papagaio, nem de um gramofone.

Nota-se aqui uma questão de competência lingüistica. Uma máquina não pensa por si, portanto, não pode criar por si jogos de linguagem, nem empregar as palavras conforme os seus usos nos jogos de linguagem corrente. Como ele explicita na seção 340: "Não se pode adivinhar como é que uma palavra funciona. Tem que se olhar para sua aplicação e aprender a partir dai". Neste sentido, o significado independe da referência e se relaciona com o comportamento dos falantes, com os usos que eles fazem da linguagem.

Mais adiante, na seção 350, coloca a questão: como comparar representações? Qual o critério para comparar o meu fazer com o de outra pessoa? Como seria possivel comparar representações de indivíduos diversos? Não podemos, neste campo, ir além dos testes públicos. Só nos resta a aplicação pública dos conceitos.

$\mathrm{O}$ que se observa como fundamental é que a linguagem não serve apenas para designar objetos por meio de palavras; ao contrário, as palavras só têm sentido no seu uso num determinado contexto. Neste sentido, os jogos de linguagem proporcionam uma multiplicidade de usos, e, em diferentes contextos, seguem-se diferentes regras. Assim sendo, não existe uma essência da frase. A essência não está circunscrita a determinados jogos de linguagem. A essência percorre uma multiplicidade de jogos. A "significação das expressões vem da função que elas exercem nas diferentes formas de práxis humana" (Oliveira, 1996:147). Desta maneira, podemos concluir afirmando que o processo terapêutico" desenvolvido por Wittgenstein nas Imvestigaçóes Filosóficas resulta num ataque direto às posições metafísicas e idealistas na tilosotia da linguagem e na semântica tradicionais.

1 Como nos ensina Arlei Moreno (2000:72-3): "Afirmamos, repetidas vezes, que Wittgenstein nào elabora um sistema filosófico, mas apenas fornece conccitos operatórios, que podem ser aplicados conforme as circunstancias, ou melhor, conforme a profundeza e a gravidade da confusào conceitual. A filosofía é, nesse sentido, concebida como uma atividade terapêutica, que procura detectar e assim clarificar situaçoes conceitualmente confusas: "Nào há um método da filosofia, mas sim métodos, como que diferentes terapias' (1.F. \$ 133$)$ ". 


\section{REFERÊNCIAS BIBLIOGRÁFICAS}

DESCARTES, René. Discurso do Método. São Paulo: Nova Cultural, 1996. (Os Pensadores)

GLOCK, Hans-Johann. Dicionário Wittgenstein. Rio de Janeiro: Jorge Zahar, 1998.

HINTIKKA, Jaakko e HINTIKKA, Merrill. Uma Investigação Sobre Wittgenstein. Campinas: Papirus, 1994.

KRIPKE, Saul. Règles et Langage Privé: Introduction au paradove de Wittgenstein. Paris: Seuil, 1996.

MORENO, Arley R. Wittgenstein: os labirintos da linguagem: ensaio introdutório. São Paulo: Moderna: Campinas: Ed. UNICAMP, 2000.

OLIVEIRA, Manfredo de Araújo. Reviravolta Lingüístico-Pragmática na Filosofia Contemporânea. São Paulo: Loyola, 1996.

SMITH, Plínio Junqueira. Como distinguir entre estados subjetivos? Mamuscrito. Vol. XVIII, n. 2, p.339-366, out. 1995.

WITTGENSTEIN, Ludwig. Tratado Lógico-Filosófico \& Investigações Filosóficas. Lisboa: Fundação Calouste Gulbenkian, 1995. 